\title{
The Body Electric: Thin-Ideal Media and Eating Disorders in Adolescents
}

\author{
by Kristen Harrison
}

The aim of this study was to replicate survey research demonstrating a correlation between adults' thin-ideal media exposure and eating disorders (Harrison \& Cantor, 1997) with a sample of 366 adolescents. Measures included interest in bodyimprovement media content, exposure to thin-ideal television and magazines, exposure to fat-character television, exposure to sports magazines, and eating-disorder symptomatology. Exposure to fat-character television, thin-ideal magazines, and sports magazines predicted eating-disorder symptomatology for females, especially older females. Exposure to fat-character television also predicted body dissatisfaction for younger males. Relationships remained significant when selective exposure based on interest in body-improvement content was controlled. Discussion centers on the importance of age and sex in moderating the effects of exposure to thin-ideal media on eating disorders.
Have you seen the fool that corrupted his own live body? or the fool that corrupted her own live body?
For they do not conceal themselves, and cannot conceal themselves.

—Walt Whitman, 1855

During the past decade, scholars and clinicians interested in the study of electronic media effects and mental health have turned their attention to the link between exposure to thin-ideal media and eating disorders (Harrison \& Cantor, 1997; Harrison, 1997; Levine \& Smolak, 1996; Stice, 1998; Stice, Schupak-Neuberg, Shaw, \& Stein, 1994; Stice \& Shaw, 1994). Content analyses (Garner, Garfinkel, Schwartz, \& Thompson, 1980; Silverstein, Perdue, Peterson, \& Kelly, 1986; Wiseman,

\footnotetext{
Kristen Harrison (PhD, University of Wisconsin-Madison) is an assistant professor in the Department of Communication Studies and Research Center for Group Dynamics, Institute for Social Research, at the University of Michigan. The author thanks Joanne Cantor for her extensive advice and support and the school administrators, teachers, and students who generously volunteered their time for this study, as well as L. Rowell Huesmann, Timothy J. Strauman, and Nicholas A. Valentino for their input regarding the method and measures used in this study. Correspondence concerning this paper should be addressed to the author at the Department of Communication Studies, University of Michigan, 2020 Frieze Building, Ann Arbor, MI 48109-1285; email: krishar@umich.edu.
} 
Gray, Mosimann, \& Ahrens, 1990) have shown that over the past 50 years, since the birth of television, female media personalities have grown steadily thinner, so that currently more than half meet criteria for anorexia nervosa (Wiseman et al., 1990).

Concerned with the effects of exposure to a severely thin body ideal on the eating behaviors of viewers, Stice and colleagues (Stice, 1998; Stice et al., 1994; Stice \& Shaw, 1994) conducted several studies on the relationship between media exposure and eating disorders. Stice et al. (1994) tested the fit of a structural equation model, including media exposure, gender-role endorsement, ideal-body stereotype internalization, body dissatisfaction, and eating-disorder symptomatology with a sample of female college undergraduates. Media exposure was significantly related to disordered eating (standardized path coefficient $=.30, p<.001$ ) . In another study of college women, Stice and Shaw (1994) found exposure to thin female magazine models to be positively related to bulimic symptomatology.

Harrison and colleagues (Harrison, 1997; Harrison \& Cantor, 1997) have also examined the exposure-disorder relationship empirically. Harrison and Cantor (1997) studied the relationship between college women's media use and eatingdisorder symptomatology and college men's media use and endorsement of thinness as a personal body ideal. The authors suggested that the social cognitive process of modeling (Bandura, 1994) was the underlying mechanism behind the media exposure-eating disorder relationship and predicted that exposure to thinness-depicting and -promoting (TDP) media, defined as fitness and fashion magazines and television programs with conspicuously thin female main characters, would predict disordered eating and thinness endorsement more strongly than would overall media exposure. Harrison and Cantor found that exposure to TDP media, especially magazines, predicted anorexia, bulimia, drive for thinness, body dissatisfaction, and ineffectiveness in women. They also found that exposure to television programs with conspicuously fat main characters predicted body dissatisfaction. These relationships remained even when selective exposure based on interest in "body improvement" media topics such as fitness and dieting was controlled; in other words, the exposure-disorder relationships were significant even for women who reported no interest in fitness and dieting as media topics. The authors argued that the exposure-disorder relationship must exist for reasons other than the simple explanation that women with eating disorders seek out media congruent with their existing diet-related beliefs. For their sample of men, the authors found that exposure to TDP media predicted endorsement of personal thinness and dieting; they did not, however, examine disordered eating in males.

Although these studies point to a consistent if modest positive correlation between thin-ideal media exposure and eating disorders, the generalizability of their findings is limited in a number of ways. First, these studies examined disordered eating in young adulthood and not adolescence, when disordered eating typically begins (American Psychiatric Association, 1994). Second, the participants represent a relatively narrow range of ages and thus analyses provide little information on age differences. Third, none of these studies examined males along with females.

The research that does exist on adolescents, media, body image, and mood (Freedman, 1984; Irving, 1990; Meyers \& Biocca, 1992; Pinhas, Toner, Ali, Garfinkel, 
\& Stuckless, 1999; Tan, 1977; Tiggemann \& Pickering, 1996) demonstrates immediate and usually problematic effects of exposure to thin-ideal media images on young women. The media effects and mental health disciplines are still in need of research examining the link between exposure to thin-ideal media and eating disorders in adolescents of different ages and both sexes. Research on males (Anderson, 1990) shows that they do suffer from eating disorders, though not as frequently as females, and, like females, they respond to social pressures to attain a lean body (American Psychiatric Association, 1994). However, content analyses like those conducted by Andersen and DiDomenico (1992) show that thinness as a physical ideal is more prevalent in women's magazines than men's, even within the same genres. Therefore, one might expect the relationship between disordered eating and exposure to media depicting the thin ideal to be stronger for females exposed to female body-ideal media than for males exposed to male body-ideal media.

Based on the research summarized to this point, three predictions are advanced:

H1: Thin-ideal television viewing will be positively associated with eating disorder symptomatology, independent of selective exposure based on interest in body-improvement television topics.

H2: Thin-ideal magazine reading will be positively associated with eating disorder symptomatology, independent of selective exposure based on interest in body-improvement magazine topics.

$\mathrm{H} 3$ : The relationships hypothesized in $\mathrm{H} 1$ and $\mathrm{H} 2$ will be weaker for males exposed to male thin-ideal media than for females exposed to female thinideal media.

A key issue here is the question of what "thin-ideal media" means. Naturally such content would include portrayals of thinness as a desirable trait in and of itself or at least a trait that accompanies other desirable traits, as when the most beautiful, desirable, and successful protagonists are also thin. Yet, the thin body ideal may be just as effectively communicated by portrayals of fatness ${ }^{1}$ as an undesirable trait, one deemed disgusting in and of itself or one that accompanies other undesirable traits such as untrustworthiness, sloppiness, and gluttony. A number of studies show that fatness is indeed rare in the mass media (Garner et al., 1980; Silverstein et al., 1986; Wiseman et al., 1990), but unfortunately there is little content-analytic research detailing exactly how overweight people are represented. Is fatness treated as a normal or even desirable trait, or is it stigmatized? Does exposure to fat media personalities foster the perception that it is permissible to be fat, or does it increase fear of fatness, thereby aggravating eating disorders? A recent content analysis of television situation comedies by Fouts and Burggraf (1999) demonstrated that overweight female characters received fewer positive

\footnotetext{
${ }^{1}$ The term "fat" is used here not to denote the actual body fat percentage or any other weight-related indicator of health or body tissue composition (for which the word "overweight" might be more appropriate), but to reflect the negative social stereotype associated with being overweight.
} 
body- and weight-related comments from male characters than did thinner female characters, a finding that suggests that overweight characters are portrayed in a less flattering light than thin characters. Given the lack of additional research on this topic, it is difficult to predict whether exposure to fat-character television programming would be positively or negatively related to disordered eating, although there is some indication that this relationship might be positive: Research by Harrison and Cantor (1997) showed that exposure to fat-character programming was positively related to body dissatisfaction in college women. This is but one finding, however, so the issue of whether fat-character programming is related to disordered-eating symptomatology is phrased as a research question:

RQ1: Does exposure to fat-character television programming predict eatingdisorder symptomatology, independent of selective exposure based on interest in body-improvement television topics?

In addition to replicating Harrison and Cantor's (1997) work on thin-ideal media, this study included measures of exposure to a little-studied type of body-relevant media, sports magazines. Research (Biddle, Akande, Vlachopoulos, \& Fox, 1996; Butcher, 1989; McNeal, 1995; Virnig \& McLeod, 1996) demonstrates that involvement in sports, especially those sports in which a lean body is not required for performance, is related to a more positive body image and lower disordered eating in adolescents. Additional research demonstrates that sports spectatorship can bolster spectators' self-confidence, mood, and self-esteem, particularly when one's team is winning (Hirt, Zillmann, Erickson, \& Kennedy, 1992). Yet, there is almost no research on the effects of exposure to sports media on the eating behaviors of adolescent viewers. In a recent study conducted with adolescent girls, Tiggemann and Pickering (1996) found no correlation between overall television viewing and body dissatisfaction or drive for thinness, but they did find that exposure to sports programming negatively predicted body dissatisfaction. The question posed in this study is whether sports magazine exposure will be related to body dissatisfaction, drive for thinness, anorexia, and bulimia in adolescents of different ages and sexes. Based on these authors' research findings, a negative correlation might be predicted, but the moderating roles of age and sex are as yet unknown, as is the potential importance of medium (television versus magazines). Therefore, this issue is phrased as a research question:

RQ2: Does sports magazine reading predict eating-disorder symptomatology, independent of selective exposure based on interest in sports magazine content?

Finally, there is reason to expect age to moderate the observed relationships. Research at the nexus of developmental psychology and media uses and effects yields numerous differences between the ways younger and older children respond to the media, especially television. Wilson and Cantor (1985), for instance, studied developmental differences in children's empathic responses to a depiction of a frightened character and found that older children (preadolescents) engaged 
in more role-taking than younger children and were also more emotionally affected by the character's fright than were younger children. Furthermore, Wilson and Smith (1998) summarized research demonstrating that not only do older children and adolescents recognize characters' emotions better than younger children, but they also develop more complex and enduring parasocial relationships with media personalities and learn from their own inferences about characters' motives instead of relying solely on overt behaviors and statements. This finding is echoed in a study by Bearison, Bain, and Daniele (1982), who found in samples of 5-6-year-olds, 7-10-year-olds, 11-14-year-olds, and adolescents over 17 that, with age, participants were better at making inferences about the nature of the social interactions they observed in a series of television scenes and better at explaining motives based on their perceptions of characters' personality traits and psychological qualities. These findings suggest that, as children get older, they acquire the skills necessary to grasp the dramatic nuances that form the intended meaning of a portrayal. Because the portrayal of thinness as an ideal trait requires the ability to make inferences (e.g., "The girl all the boys like is thin and the girl they make fun of is fat, so thin must be good and fat must be bad"), the ability to read between the lines of such portrayals should facilitate understanding and therefore acceptance of the message. Moreover, research shows that adolescents must first recognize implicit value statements (e.g., "thin is good") in the media and then see them as functional or important in achieving success (e.g., "I will gain social approval by losing weight") in order to accept these values (Tan, Nelson, Dong, \& Tan, 1997). Because of their cognitive sophistication, older adolescents should find this easier to do than younger adolescents.

On the other hand, research demonstrates that older adolescents better understand the difference between media fantasy and reality than do younger adolescents (Dorr, Kovaric, \& Doubleday, 1990) and should therefore have the tools to be more critical media consumers. Likewise, Doubleday and Droege (1993) summarized research demonstrating that older adolescents are better able than younger adolescents to distinguish between program and commercial content. These abilities should allow them to understand what is being "sold" to them as audience members, increasing their capacity to resist unrealistic media messages suggesting that they should have a certain body type. Given these seemingly divergent lines of developmental research, it is difficult to predict whether participant age (defined here as grade level) should increase or decrease the media exposure-eating disorder relationship, but it seems clear that age might have some moderating effect. Thus the issue is phrased as a research question:

RQ3: What is the moderating role of age (defined as grade) in the observed relationships?

\section{Method}

\section{Participants}

Adolescents were the population chosen for this study because adolescence is a period in life when changing bodies and increasing awareness of social standards 
make body image especially salient (Freedman, 1984). Moreover, most eating disorders begin in adolescence (American Psychiatric Association, 1994). To facilitate comparisons between participants at distinct points in adolescence, the sample consisted of three age groups: 6th graders (average age, 11.5), 9th graders (average age, 14.6), and 12th graders (average age, 17.8). These grades were chosen to mark the lower, middle, and upper bounds of adolescence as time periods in the life span rather than significant social or emotional developmental stages. Although eating disorders affect a greater number of females than males, the prevalence of eating disorders among males is on the rise (American Psychiatric Association, 1994; Brand, Rothblum, \& Solomon, 1992), thus the sample consisted of both males and females.

I obtained parental permission to test participants in school, and all participants signed their own assent forms at the start of data collection. The youngest age group came from a single middle school, whereas the two older groups were recruited from adjoining junior high and high schools. All three schools were located in a medium-sized Midwestern city, and students were mostly middleclass. This method of convenience sampling was appropriate because the primary aim of this study was not to describe the prevalence of eating disorders among adolescents, but to investigate the relationships between media use and disordered eating among adolescents who were likely to exhibit a range of eating disorder symptoms. Approximately 130 participants in each age group were recruited for the study, and the majority of participants obtained permission and participated. The total sample size was 366 (49.7\% female), comprised of 123 6th graders, 114 9th graders, and 129 12th graders. The majority of participants were European-American (81.8\%), followed by 9.2\% African-American and 7.0\% AsianAmerican.

\section{Procedure}

A team of three to five research assistants visited participants in class and led them through the questionnaire. To minimize talking, they instructed participants to turn their questionnaires over when complete and wait until their classmates were done. A research assistant then collected the questionnaires, thanked the participants, and left. Within a week teachers were given a brief paragraph to read to their students explaining the purpose of the study and the relationships of interest.

\section{Measures}

Media exposure. I measured overall television exposure as hours viewed on an average weekday, an average Saturday, and an average Sunday. The first item was multiplied by five and added to the second two items to form an index of weekly television viewing. Because this was a single-index variable, I did not compute reliability. Viewing of specific television programs and genres was measured with self-report items assessing frequency of viewing $(0=$ never to $4=$ regularly $)$ each of 15 Nielsen top-rated programs for the winter/spring season of 1997. I chose these programs according to three criteria. First, they were among the top 50 programs viewed by adolescents during that time period. Second, they contained a diverse sampling of the body types featured among characters in popular televi- 
sion entertainment. Third, because informal pretesting showed that 6th graders had difficulty remembering their viewing patterns for a large list of programs, only a limited number of programs could be included in the questionnaire. Exhaustion appeared to hamper their recall by the time they reached the 20th show in a list. These three criteria converged in the selection of the 15 programs listed in Table 1. Magazine exposure was also measured with self-report items. Participants answered the following question: "In an average month, how many magazines do you read or look at? This includes magazines that come to your classroom or home, and magazines you buy or borrow from friends." Participants were then asked to estimate the number of issues they regularly looked at or read each month (from 0 to 8 or more) in five categories: news and current events, health and fitness, fashion, entertainment and gossip, and sports and activities. I chose these categories because they feature a wide array of body types.

To obtain an index of thin-ideal television viewing and magazine reading, I conducted a separate survey with a sample of 70 college undergraduates $(66 \%$ female) in a communication research course. College students are just out of adolescence (some were only 1 year older than the oldest members of the adolescent sample), and they are not as easily exhausted as adolescents by lengthy rating procedures. They also have the more highly developed critical evaluation skills necessary to give informed body-size ratings. Early adolescents, for instance, may feel that a program's stick-thin characters are "normal" and that their own normal bodies are fat because they have yet to fully understand the commercial goals and aesthetic prejudices behind their country's media offerings. College students were expected to provide more objective ratings based on their understanding of the differences between the appearance of television characters and magazine models and that of "real people." Respondents were asked to rate the body sizes (ranging from $1=$ conspicuously thin to $4=$ average to $7=$ conspicuously fat) of the male and female main characters in a variety of popular television programs, including but not limited to those listed in Table 1, as well as the body sizes of male and female models and celebrities appearing in each of the five magazine genres in Table 1 . They were told to consider a particular body size "conspicuous" if at least one main character was represented on the program in a way that drew attention to his or her body's fatness or thinness as part of his or her character makeup. ${ }^{2}$

The mean body-size ratings of the undergraduate respondents were used in conjunction with adolescents' frequency-of-exposure measures to create three key

\footnotetext{
2 Raters were introduced to the task of rating the body sizes of media personalities with the following passage:
}

\footnotetext{
You have probably noticed that some TV programs feature very skinny characters and some feature very overweight characters. Although such casting may reflect an effort on the part of producers to display a wide range of body types, it is more often done to make a statement about the character's personality, experiences, and attractiveness or lack thereof. The purpose of this survey is to measure your opinions about the body types of main characters on some of today's most popular TV shows. My colleagues and I will be using your responses to classify shows along a scale of "conspicuously thin" to "conspicuously fat." We've chosen these particular terms not to stigmatize people of these body types, but to reflect common social conceptions of them. On the following pages you will find the names of 25 TV shows. For each show, we are interested in
} 
variables for the adolescent sample: thin-ideal television exposure, thin-ideal magazine exposure, and fat-character television exposure. The thin-ideal exposure variables are discussed first. To clarify interpretation of analysis, I recoded participants' ratings so that higher numbers represented greater thinness. Table 1 features the mean ratings of main characters in each program and magazine genre. These mean ratings were multiplied by frequency-of-viewing scores for each adolescent participant and the resulting cross products added together for each participant. Thus, in the tradition of Huesmann and associates (e.g., Huesmann, Moise, \& Podolski, 1997), the thin-ideal exposure variables were calculated to reflect both amount of exposure and extremity of content. Because body-size ratings of less than 4 indicated "greater fatness" and not "less thinness," each body-size mean rating was multiplied by the corresponding frequency-of-exposure variable only for programs or magazines with average scores greater than 4 (i.e., thinner than average). For programs with average scores less than 4 (i.e., fatter than average), the frequency variables were multiplied by zero; there were no mean ratings of exactly 4.00. I followed the same procedure for the five magazine genres to create a thin-ideal magazine exposure index.

To create an index of fat-character television exposure, I used the original rating scale $(1=$ conspicuously thin, $7=$ conspicuously fat $)$ and multiplied the body-size score by the frequency-of-viewing variable only for programs with average scores greater than 4 (i.e., fatter than average). For programs with average scores less than 4 (i.e., thinner than average), the frequency variables were multiplied by 0 , thereby eliminating those programs. Again, there were no mean ratings of exactly 4.00. An index of exposure to fat-character magazines could not be created because none of the mean body-size ratings of magazine personalities were in the "fat" range of the scale.

\footnotetext{
knowing how you would classify the body types of the main characters on that show, both male and female. For each show, you will find a scale ranging from "conspicuously thin" to "conspicuously fat" for both males and females. By "conspicuous," we mean that it seems that the show's producers are making an effort to draw attention to the character's body shape or weight, through a variety of dramatic mechanisms such as clothing, comments, or storylines. By "thin," we mean a character who is obviously slender and/or has the appearance of very little body fat. (Therefore lean, muscular men, not just skinny men, would be classified as thin.) By "fat," we mean the appearance of greater-than-average body fat. By "average," we mean the normal human frame for each sex, neither conspicuously thin nor conspicuously fat. So, for each show, please think about how you would classify the main female and male characters. Please note: Most shows will have some average characters, so please think about the more extreme body types portrayed on the show. The "average" section of the scale should be reserved for shows that have neither conspicuously thin nor fat characters. Also, because there are so few shows with conspicuously fat main characters, if a show has all three types of bodies, fat should dominate your classification. EXAMPLE: Back in the early '80s there was a show called Gimme a Break. It portrayed a conspicuously overweight woman ("Nell") in the midst of an average-to-thin family. If you were classifying this show, you might classify its depiction of the male body as somewhere near average (if the primary male main characters were neither conspicuously thin nor conspicuously fat) and its depiction of the female body as conspicuously fat. Even though there were other average and thin female characters, the rarity of an overweight female main character in this shows qualifies the female body portrayal of the show to be classified as somewhere near conspicuously fat. Of course, your opinion about how thin or fat main characters are depends on your particular view of thin, average, and fat. Circle the vertical mark representing your response. OTHER DIRECTIONS: If you come across a show that you have never seen, simply check the line labeled "never seen." For talk shows, consider both the host and the typical guests to be main characters. If a host is overweight but has skinny guests of the same sex, think about which is more salient to the viewer. If a show features characters whose weight has changed over time, think about how they looked during the past 2 years. MAGAZINES: Now, please rate the following magazine genres the same way you rated the TV shows. Instead of characters, think of the typical male and female models and celebrities featured in the magazines.
} 
Table 1. Mean Body-Size Ratings for Media Personalities in 15 Television Programs and 5 Magazine Genres $(N=70)$

\begin{tabular}{|c|c|c|c|c|c|c|}
\hline \multirow[b]{3}{*}{ Type of Media } & \multicolumn{5}{|c|}{ Media Personalities } & \multirow{3}{*}{ Range } \\
\hline & \multirow[b]{2}{*}{$M$} & \multicolumn{2}{|c|}{ Female } & \multicolumn{2}{|r|}{ Male } & \\
\hline & & $S D$ & Range & $M$ & $S D$ & \\
\hline \multicolumn{7}{|l|}{ Television Programs } \\
\hline Melrose Place & 6.67 & 0.54 & $5-7$ & 5.87 & 1.07 & $3-7$ \\
\hline Friends & 6.48 & 0.66 & $5-7$ & 5.43 & 0.99 & $4-7$ \\
\hline Beverly Hills 90210 & 6.28 & 0.77 & $4-7$ & 5.32 & 1.10 & $3-7$ \\
\hline Suddenly Susan & 5.76 & 0.87 & $4-7$ & 4.72 & 0.93 & $3-7$ \\
\hline Caroline in the City & 5.50 & 1.13 & $3-7$ & 4.85 & 0.92 & $4-7$ \\
\hline Seinfeld & 5.10 & 1.01 & $3-7$ & 3.75 & 1.15 & $1-7$ \\
\hline Single Guy & 5.06 & 0.90 & $4-6$ & 4.47 & 0.62 & $4-6$ \\
\hline Mad About You & 5.02 & 0.96 & $3-7$ & 4.25 & 0.83 & $3-7$ \\
\hline$E R$ & 4.75 & 0.93 & $3-7$ & 4.61 & 0.88 & $3-7$ \\
\hline Sally Jesse Raphael & 3.88 & 0.77 & $2-5$ & 3.88 & 0.55 & $3-5$ \\
\hline Grace Under Fire & 3.56 & 0.95 & $2-6$ & 3.47 & 0.76 & $2-5$ \\
\hline Ricki Lake & 2.31 & 0.96 & $1-6$ & 3.28 & 0.92 & $1-5$ \\
\hline Drew Carey Show & 2.28 & 1.50 & $1-7$ & 1.48 & 0.54 & $1-3$ \\
\hline Rosie O'Donnell & 2.08 & 1.10 & $1-6$ & 4.11 & 0.90 & $1-6$ \\
\hline Roseanne & 1.29 & 0.73 & $1-6$ & 1.39 & 0.77 & $1-6$ \\
\hline \multicolumn{7}{|l|}{ Magazine Genres } \\
\hline Fashion & 6.81 & 0.53 & $5-7$ & 6.30 & 0.90 & $4-7$ \\
\hline Health \& fitness & 6.56 & 0.74 & $4-7$ & 6.33 & 0.88 & $4-7$ \\
\hline Sports \& activities & 6.38 & 0.91 & $3-7$ & 5.97 & 1.00 & $4-7$ \\
\hline Entertainment \& gossip & 6.21 & 0.85 & $4-7$ & 5.64 & 1.04 & $4-7$ \\
\hline News \& current events & 4.34 & 0.76 & $3-7$ & 4.03 & 0.66 & $2-6$ \\
\hline
\end{tabular}

Note. Rating scales are coded here to range from $1=$ conspicuously fat to $7=$ conspicuously thin with $4=$ average. Ranges reported in the table represent the low and high scores given by participants for each program or magazine genre. 
I calculated all thin-ideal and fat-character exposure variables separately for male and female participants using mean ratings for same-sex media personalities only, thus creating six variables: female thin-ideal television, thin-ideal magazine, and fat-character television exposure for female adolescent participants, and thinideal television, thin-ideal magazine, and fat-character television exposure for male adolescent participants.

The validity and reliability of these measures, because of their unique composition, must be approximated through means other than those typically used in scale validation and reliability estimation (e.g., confirmatory factor analysis, Cronbach's $\alpha$ ). ${ }^{3}$ The standard deviations and ranges of the mean body-size ratings reported in Table 1 suggest that these measures are internally consistent. For most programs and magazines, the standard deviation and range of reported responses are quite small, indicating consistency in rater perceptions. Certain programs are less consistent, however. The Drew Carey Show, for instance, has a large standard deviation and received every body-size rating possible. Other programs (Sally Jesse Raphael, Grace Under Fire) received body-size ratings in both the "fat" and "thin" ranges, suggesting rater disagreement over which characters were "main" characters or whose bodies were most relevant or salient. Because real-life television programs feature multiple characters, and because different aspects of a character are salient to viewers, some imprecision in measures that employ subjective ratings is to be expected. Indeed, if an individual program such as Roseanne features fat main characters (Roseanne) as well as thin main characters (Roseanne's sister Jackie), raters may score the show at the opposite extremes of the scale depending on which character they were considering. However, on the group level this imprecision is not necessarily a detriment because the measure itself is designed to correct for such imprecision: Inconsistent ratings average themselves out, resulting in a group mean score near "average." Recall that I created the thinideal and fat-character variables separately, so that programs with mean scores near "average" were recoded to equal 0 or near-0 (since average indicated no thinness or fatness). Thus, inconsistently scored programs with means near average contributed much less to the variation of the thin-rewarded and fat-punished variables than did the consistently scored, more content-extreme programs like Friends or Melrose Place. Therefore, the programs that the college sample perceived most similarly carried more weight in the final thin-ideal and fat-character exposure indexes than the programs for which there was disagreement. This was appropriate because programs that are viewed by most people as having thin main characters will be more important in the formation of body-related attitudes

\footnotetext{
3 Estimators of internal consistency, such as Cronbach's $\alpha$, are not appropriate here because the revelant variables were not constructed from multiple indicators of some unitary underlying construct. The relevant variables were sums of the cross products between the mean body-size rating for each television program or magazine genre and each participant's exposure score for that program or genre. In other words, the values used to create each cross product were a constant and a single exposure score for a unique program or genre, multiplied together. Thus, calculating an $\alpha$ value for the cross products would yield, not an estimate of internal consistency, but an estimate of how much exposure to one program or genre was correlated with exposure to the others, a relationship not of interest in this paper.
} 
and eating behaviors than programs viewed as having thin main characters only by some. ${ }^{4}$

Selective exposure based on interest. Selective exposure to specific types of media content based on interest in that content was measured with 10 items assessing whether participants would be more or less interested ( $1=$ less, 2 = neither, $3=$ more) in a new television show and magazine if they covered a variety of topics. Three of these topics were relevant to this study: fitness, dieting, and sports. I added the fitness-interest and dieting-interest variables together to create one "body-improvement" television interest variable and one "body-improvement" magazine interest variable. Because there were only two indicators summed to create each body-improvement interest variable, Cronbach's $\alpha$ could not be computed. Bivariate correlations were substantial, however: The correlation between interest in fitness and dieting as television topics was $.57, p<.001$, and the corresponding correlation for magazine topics was .52, $p<.001$. Interest in sports was measured for magazines only.

Eating-disorder symptomatology. The Children's Eating Attitudes Test (ChEAT; Maloney, McGuire, \& Daniels, 1988) served as the anorexia measure. This scale is a shortened and rewritten version of the Eating Attitudes Test (Garner \& Garfinkel, 1979) and has been used as a reliable measure of extreme restrained eating for children as young as 8 years old (Maloney et al., 1988). A sample item is "I think a lot about wanting to be thinner." Possible responses ranged from $0=$ never to 5 $=$ always. Cronbach's $\alpha$ for the original 26-item scale was .83; however, confirmatory factor analysis yielded a fitting model with items 1, 10, 11, 12, 14, 22, and 23, $C F I=.98, \alpha=.90$, so the reduced scale was used in subsequent analyses.

I used three independent subscales of the Eating Disorders Inventory (EDI; Garner, Olmstead, \& Polivy, 1984) to measure bulimic symptomatology, body dissatisfaction, and drive for thinness. The structure of EDI items is similar to that of ChEAT items, although the EDI is adult specific. Therefore, certain items were rewritten to be child appropriate (e.g., "I exaggerate or magnify the importance of weight" was rewritten as "My weight seems almost too important to me"). Sample items include "I think my hips are too big" (body dissatisfaction), "If I gain a pound, I worry that I will keep gaining" (drive for thinness), and "I eat only a little around others and stuff myself when they're gone" (bulimia). For the 9-item body dissatisfaction scale, confirmatory factor analysis yielded a fitting model with items 3, 4, 5, 7, and 9, CFI $=.97, \alpha=.91$. For the 7-item drive for thinness scale, I obtained a fitting model with items $2,3,4,5,6$, and 7, $C F I=.97 \alpha=.90$. For the 6-item bulimia scale, I obtained a fitting model with items 1, 2, 3, 4, and 6, CFI = $.95, \alpha=.67$. For all three of these measures, the reduced scales were more reliable than the original scales, so the reduced scales were used in subsequent analyses.

4 This does not mean, of course, that certain programs and characters, not to mention magazines and models, are not more salient to or more important in the lives of some media users than others. Individual differences such as these are not the central concern of this study, which was aimed at understanding trends at the aggregate level, but they are sure to prove important in future research on this topic. 
Table 2. Means for Media Interest, Media Exposure, and Eating-Disorder Symptomatology by Sex

\begin{tabular}{lccccc} 
Variable & Range & Female $M$ & Male $M$ & $t$ & $d f$ \\
\hline $\begin{array}{l}\text { Interest } \\
\quad \text { Thin-oriented TV }\end{array}$ & $1-3$ & 1.97 & 1.55 & $6.00^{* * *}$ & 324 \\
$\quad$ Thin-oriented magazines & $1-3$ & 2.05 & 1.59 & $6.52^{* * *}$ & 325 \\
$\quad$ Sports magazines & $1-3$ & 1.18 & 1.30 & $-2.82^{* *}$ & 326 \\
& & & & & \\
$\begin{array}{l}\text { Exposure } \\
\text { TV viewing per week }\end{array}$ & Hours & 15.52 & 18.74 & $-2.49^{*}$ & 323 \\
$\quad$ Thin-ideal TV & - & 53.53 & 30.80 & $7.12^{* * *}$ & 322 \\
$\quad$ Fat-character TV & - & 28.82 & 22.13 & $3.42^{* * *}$ & 325 \\
$\quad$ Thin-ideal magazines & - & 36.36 & 17.58 & $7.18^{* * *}$ & 324 \\
$\quad$ Sports magazines & $0-8$ & 1.49 & 2.94 & $-5.97^{* * *}$ & 325 \\
& & & & & \\
Disordered Eating & $0-5$ & 1.67 & 0.76 & $8.19^{* * *}$ & 326 \\
$\quad$ Anorexia & $0-5$ & 0.84 & 0.66 & $2.29^{*}$ & 326 \\
$\quad$ Bulimia & $0-5$ & 1.38 & 0.57 & $6.85^{* * *}$ & 325 \\
$\quad$ Drive for thinness & $0-5$ & 2.58 & 1.53 & $6.80^{* * *}$ & 323 \\
$\quad$ Body dissatisfaction & & & & & \\
\hline
\end{tabular}

Note. Thin-ideal TV exposure, fat-character TV exposure, and thin-ideal magazine exposure variables are products between participants' amount of exposure and college students' body-size ratings, and thus do not have meaningful ranges.

${ }^{*} p<.05,{ }^{* *} p<.01,{ }^{* * *} p<.001$.

\section{Results}

\section{Descriptive Statistics}

Means for interest in body-improvement media topics, media exposure, and eating-disorder variables are reported in Table 2 . Females reported significantly more interest in body-improvement television and magazine topics than males, whereas males reported significantly more interest in sports topics and exposure to sports magazines than females. Females also scored significantly higher than males on measures of exposure to thin-ideal television and magazine content, fat-character television content, anorexia, bulimia, drive for thinness, and body dissatisfaction.

Zero-order correlations between all variables are reported in Table 3. For both sexes, I correlated hours of television viewing per week with exposure to thinideal and fat-character television programming. Thus, it is possible that overall television viewing would underlie any significant correlations found between thinideal or fat-character programming and disordered eating. The following analyses involving thin-ideal and fat-character programming, then, employ controls for overall television exposure. For females especially, interest in body-improvement media may confound the relationships between the media exposure variables and the eating-disorder variables because such interest was significantly correlated with 
media exposure variables and with select eating-disorder variables. The following analyses therefore also control for interest in body-improvement media.

\section{Testing of Predictions and Research Questions}

To test hypotheses 1,2, and 3, I carried out separate but identical hierarchical multiple regression analyses for females and males. To control the influence of grade and interest, I entered grade on the first step and the interest variables on the second. For the television analyses, I entered overall television exposure on the second step along with interest. Finally, I entered the media-exposure variables on the third step and terms representing the interactions between grade and each media exposure-variable on the fourth step to determine whether relationships differed by participants' grade. Anorexia, bulimia, drive for thinness, and body dissatisfaction served as separate criterion variables.

H1. Thin-ideal television exposure will positively predict disordered-eating symptomatology independent of interest in body-improvement television content.

A summary of these analyses is presented in Table 4. For females, overall television viewing positively predicted bulimia, and interest in body-improvement television content positively predicted anorexia, drive for thinness, and body dissatisfaction. Controlling for these variables, exposure to thin-ideal television did not predict eating-disorder symptomatology, but exposure to fat-character television did predict bulimia. There were no significant interactions between grade and television exposure. Thus, for all females, exposure to fat-character television content was a positive and significant predictor of bulimia.

For males, interest in body-improvement television content positively predicted anorexia and drive for thinness. Controlling for overall television viewing and interest, neither of the television exposure variables predicted eating-disorder symptomatology. There was, however, a significant interaction between grade and exposure to fat-character programming in predicting body dissatisfaction. For 6thgrade males, $\beta=.29, p<.05$; for 9th-grade males, $\beta=-.20$ (n.s.); and for 12 thgrade males, $\beta=-.21$ (n.s.). The 6th-grade $\beta$ was significantly different from both the 9th- and 12th-grade $\beta s, p<.05$, thus there was a significant positive relationship between exposure to fat-character television and body dissatisfaction for 6thgrades males, but not for older males. In summary, there was no support for either sex for the hypothesis that exposure to thin-ideal television programming would predict disordered eating when controlling for the influence of overall television exposure and interest in body-improvement television content.

H2. Thin-ideal magazine exposure will positively predict eating-disorder symptomatology independent of interest in body-improvement magazine content.

A summary of these analyses is presented in Table 5. For females, interest positively predicted anorexia, drive for thinness, and body dissatisfaction. Controlling for interest, exposure to thin-ideal magazine content positively predicted anorexia only. There was, however, a significant interaction between grade and exposure 


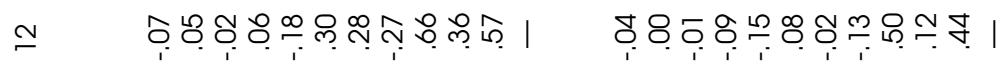

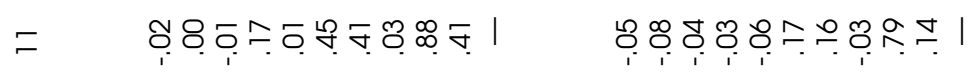

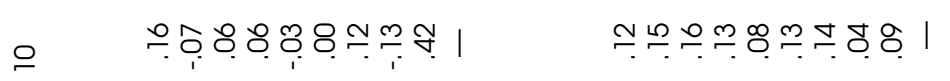

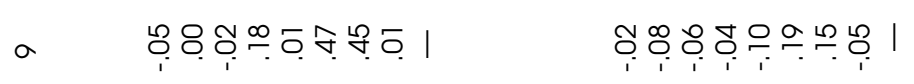

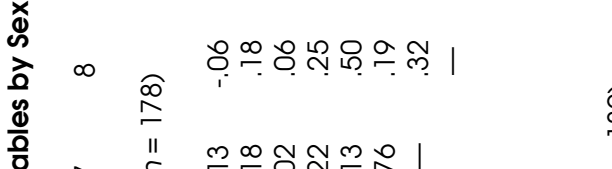

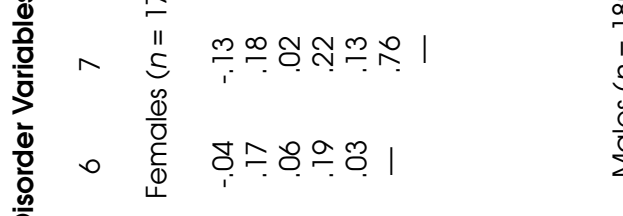

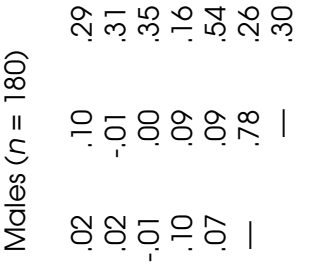

サำๆ

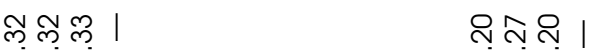

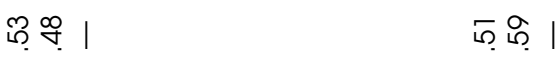

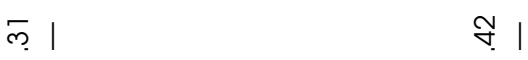

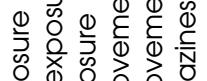

(1) 0 O

Oำ

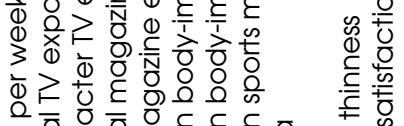

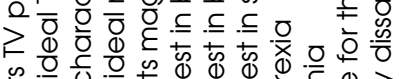

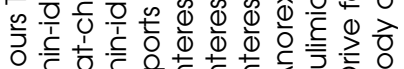




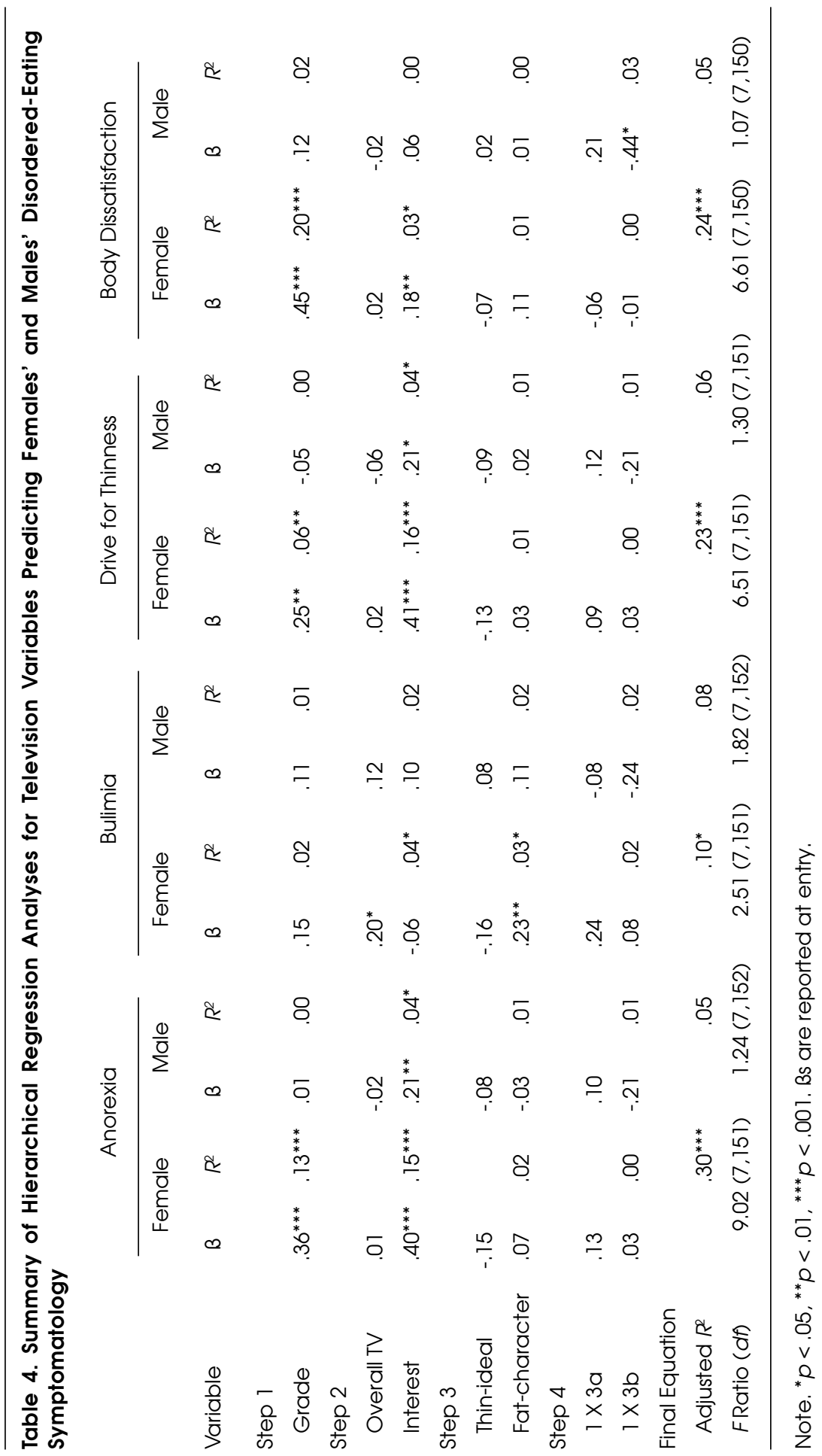




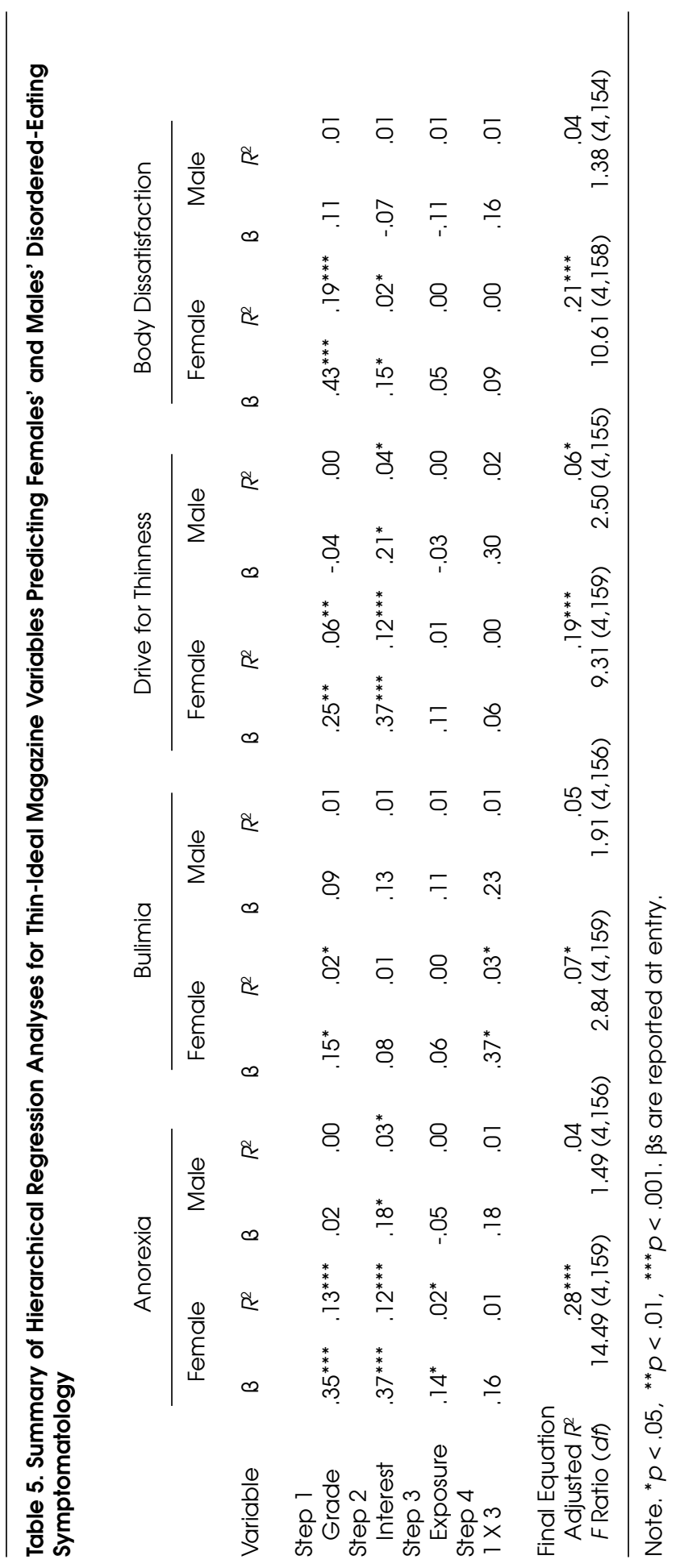


predicting bulimia. For 6th-grade females, $\beta=-.23$ (n.s.); for 9th-grade females, $\beta$ $=.31, p<.05$; and for 12th-grade females, $\beta=.24, p<.05$. Both the 9th- and 12thgrade $\beta$ s were significantly different from the 6th-grade $\beta, p<.05$. Thus, for 9thand 12th-grade females only, exposure to thin-ideal magazine content was a positive and significant predictor of bulimia.

For males, interest in thinness-oriented magazine content positively predicted anorexia and drive for thinness. Controlling for interest, thin-ideal magazine exposure did not predict eating-disorder symptomatology, and there were no significant interactions between grade and exposure. In summary, the data supported the second hypothesis for all females in predicting anorexia and for 9th- and 12thgrade females in predicting bulimia.

H3. The observed relationships between thin-ideal media exposure and eating-disorder symptomatology will be weaker for males than for females.

Given the lack of significant findings in Table 4, it is difficult to say whether the nonsignificant relationships for thin-ideal television are "stronger" for females than for males. In Table 5, the relationship between thin-ideal magazine exposure and anorexia is higher for females $(\beta=.14, p<.05)$ than for males $(\beta=-.05$, n.s.); the difference between slopes is significant at $p<.05$. Moreover, the term representing the interaction between grade and thin-ideal magazine exposure was marginally higher for females $(\beta=.37, p<.05)$ than for males $(\beta=.23$, n.s. $), p<.10$. A broader indication of whether the media variables played a larger role in predicting disordered eating for females than for males can be found in the adjusted $R^{2} \mathrm{~S}$ from the final equations. In Table 4 , the final variance for females ranges from .10 to .30, whereas for males it ranges from .05 to .08. In Table 5, the final variance for females ranges from .07 to .28 , whereas for males it ranges from .04 to .06 . It appears that the media variables (including interest and, for the television analyses, overall television exposure) indeed contributed to more of the final variance in disordered eating for females than for males.

RQ1. Does exposure to fat-character television programming predict eatingdisorder symptomatology independent of the influence of interest in bodyimprovement television content?

The findings summarized above for Hypothesis 1 answer this question in the affirmative for bulimia only: Fat-character television exposure positively predicted bulimia for all females and for the youngest (6th-grade) males.

RQ2. Does exposure to sports magazines predict eating-disorder symptomatology independent of interest in sports as magazine content?

A summary of these analyses is presented in Table 6. For females, interest in sports magazines negatively predicted body dissatisfaction. Controlling for interest, exposure to sports magazines failed to predict eating-disorder symptomatology, but there was a significant interaction between grade and exposure in predicting body dissatisfaction. For 6th-grade females, $\beta=-.11$ (n.s.); for 9th-grade 


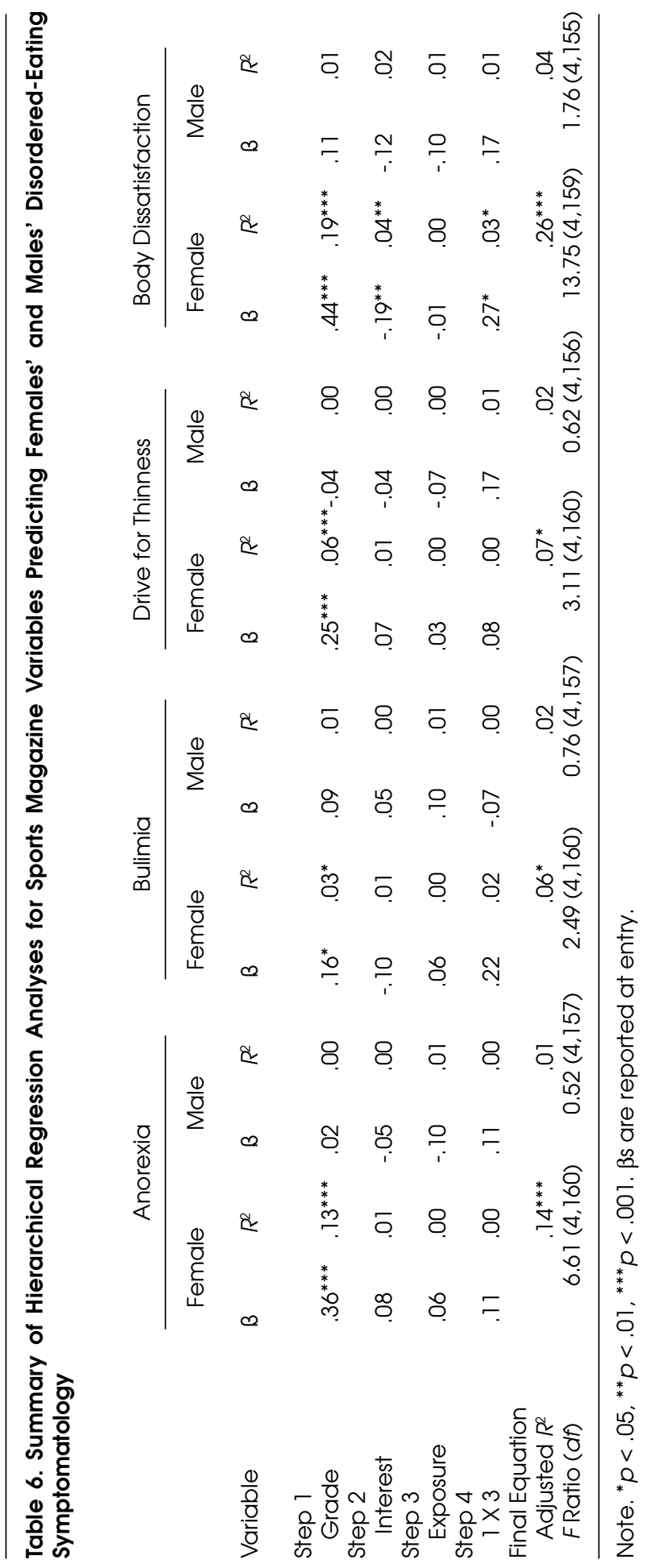


females, $\beta=-.12$ (n.s.); and for 12th-grade females, $\beta=.35, p<.05$. There were no significant findings for males. In summary, the answer to the second research question is that sports magazine exposure was positively related to body dissatisfaction, for 12th-grade females only.

RQ3. Will grade moderate the observed relationships between media exposure and eating-disorder symptomatology?

Tables 4, 5, and 6 demonstrate that grade plays a significant role in moderating the relationships between media exposure and disordered eating, especially for males. Indeed, the only main effects observed in the complete set of analyses were for females (fat-character television exposure predicting bulimia and thin-ideal magazine exposure predicting anorexia), and the only significant relationship observed at all for males appeared in the form of a single interaction (fat-character programming predicting body dissatisfaction for the youngest males). In summary, grade ( 9 and above) reduces the positive relationship between fat-character programming exposure and body dissatisfaction among males and increases the positive relationship between thin-ideal magazine content exposure and bulimia among females. Grade (12) also increases the positive relationship between sports magazine exposure and body dissatisfaction among females.

\section{Discussion}

\section{Summary of Findings}

The first hypothesis was not supported: Exposure to thin-ideal television content did not predict disordered eating. Only exposure to fat-character television content was a significant positive predictor-of bulimia (for all females) and body dissatisfaction (for 6th-grade males). This finding is consistent with Harrison and Cantor's (1997) demonstration that the only significant television predictor of eating-disorder symptomatology in college women is exposure to programs with conspicuously fat female main characters. The second hypothesis was supported for anorexia (for all females) and bulimia (for 9th- and 12th-grade females), but not for males. The third hypothesis, which predicted sex differences, was supported by way of comparison of the significant slope coefficients for males and females, but because there were so few of these, conclusions about sex differences must be considered tentative. The question of whether sports magazine exposure would predict eating-disorder symptomatology was answered with analyses demonstrating a positive relationship for 12th-grade females only. All of these relationships were significant controlling for (a) selective exposure to the relevant media sources based on interest in their body-improvement content, and (b) overall television exposure (for the television analyses). The main findings of this study can be reduced in the following manner: For females, exposure to fatcharacter television content is related to increased bulimia, whereas exposure to thin-ideal magazine content is related to increased anorexia and, among 9th- and 12th-grade females, increased bulimia. Sports magazine exposure is related to 
increased body dissatisfaction among 12th-grade females only. For males, the only significant finding is that exposure to fat-character programming is related to increased body dissatisfaction among 6th-grade males. Thin-ideal media exposure and sports magazine exposure bore no relationship to eating-disorder symptomatology for males.

When grade significantly moderates the observed relationships for females, it acts to increase the positive relationship between the exposure and disorder variables. For males, grade acts to decrease the positive relationship between the exposure and disorder variables. How is one to interpret this pattern? When relationships become more positive with age, it suggests an increase in the importance of media exposure to the development of eating disorders. In light of previously summarized research on college women, the data presented here for females suggest that thin-ideal media exposure may gain strength as a factor in the development of eating disorders as females reach midadolescence (9th grade). Such a pattern is consistent with research demonstrating the increase in disordered eating through the course of adolescence (American Psychiatric Association, 1994). Why then would such a relationship decrease with age for males? One possible explanation is that for early-adolescent boys the most salient body-relevant theme on television is the ridiculing of fatness rather than the adoration of thinness or leanness. Children of this age are most likely familiar with the stigma of fatness, but may not yet fully understand the adult body aesthetic favoring thinness. Moreover, most early adolescent boys have yet to develop physical characteristics stereotypical of men, such as angular features and muscle definition, and may therefore feel that the round and "feminine" bodies of the fat male characters they view on television match their own. To substantiate this argument, one would need to demonstrate that such bodies are in fact ridiculed on television and that this ridicule leads to body dissatisfaction in early adolescent male viewers. The lack of such research is lamentable, as future efforts to extend the findings presented here would benefit greatly from the opportunity to draw on content analyses of both female (e.g., Fouts \& Burggraf, 1999) and male fatness in the media.

It is important to remember that eating disorders are a complex physical and social problem, and that the exposure-disorder relationship is most likely bidirectional. Media users may be affected by what they view, but they also selectively expose themselves to media content that is congruent with their existing worldview. Although the main focus of this study was the exposure-disorder relationship independent of this type of selective exposure, the sheer number of significant standardized regression coefficients reported in the tables for the interest variables suggests that selective exposure based on interest, independent of media exposure, is worthy of further investigation from a uses and effects perspective. If exposure to thin-ideal media influences the development of eating disorders, then selective exposure to these media is likely to be an equally important outcome of disordered eating. In other words, thin-ideal media may aid in the perpetuation of eating disorders in part because people with eating disorders seek them out.

Indeed, a common counterargument to the assertion that thin-ideal media exposure causes eating disorders is that people with eating disorders seek out these media because these media reflect the disordered audience's worldview, give 
justification to its concerns, and provide practical information on how to continue to lose weight or avoid getting fat. The purpose of measuring interest in fitness and dieting as body-improvement media topics in this study was to reduce the influence of exposure that is selective in the following way: It is based on attraction to programs and magazines that help one learn about dieting and exercise in order to continue one's "body-improvement" regime. Such selective exposure is most likely at the crux of the reason why young people with eating disorders seek out thin-ideal media. However, there are other reasons why individuals with body issues may be attracted to programs and magazines with conspicuously thin or conspicuously fat characters, celebrities, and models, even when these media personalities are not involved in fitness and dieting. An interest in fashion, for instance, may lead an adolescent to selectively expose her- or himself to such media offerings. In fact, a study by Petersons, Phillips, and Steinhaus (1996) showed that a sample of female undergraduate fashion merchandising majors, who ostensibly pay greater attention to fashion media than nonmajors, had a significantly lower mean body mass index than controls. Therefore, controlling selective exposure as it was operationalized in this study helps limit the overall influence of selective exposure, but does not necessarily eliminate it. Researchers interested in continuing to explore the role of selective exposure in the media exposure-eating disorder relationship would do well to operationalize selective exposure in a variety of ways so that they can (a) control a larger portion of the selective exposure influence, and (b) compare the different reasons for exposure to see which is most important in facilitating the media exposure-eating disorder relationship.

As expected, significant media exposure-eating disorder relationships were stronger for females than for males. There was no evidence that male thin-ideal media have any influence on the eating-disorder-related attitudes and behaviors of adolescent males. There are a number of reasons why this may be. First, leanness as a characteristic in male media personalities may be perceived differently by males than thinness in female media personalities is perceived by females. Leanness in males implies the loss of body fat without a necessary accompanying loss in muscle mass, weight, bulk, dimensions, or general size. In fact, these parameters may even increase with leanness. Thinness in females, in contrast, implies the loss of body fat along with a general reduction in pounds, inches, dress sizes, or other parameters representing total body volume. Although it may be unlikely that adolescents think in these terms, a growing adolescent boy knows that leanness for males is an additive rather than subtractive process: If he lifts weights and exercises he will gain weight, gain muscle, gain inches in his bicep and chest measurements, and so on. Weight gain, then, may be an attractive prospect for an adolescent boy, and exposure to media offerings depicting the lean male body ideal is not likely to be associated with affirmative answers to eating-disorder scale items such as, "If I gain a pound I worry that I will keep on gaining." A growing adolescent girl, in contrast, is learning that thinness for females is a subtractive process: She is growing anyway, and her body threatens to take up "too much space" if she does not monitor its growth with diet and strategic (calorie-burning, not bulkbuilding) exercise. Exposure to the extremely thin female body ideal (Garner et al., 1980; Silverstein et al., 1986; Wiseman et al., 1990) in the media is therefore 
likely to result in affirmative responses to items asking about anxiety at the prospect of gaining a pound.

A second possible reason why male thin-ideal media exposure was not related to disordered-eating symptomatology in males could be that the body-size ratings of the independent sample of raters could have reflected the lean male ideal or simple skinniness. The instructions given to the sample of undergraduate raters stated that "lean, muscular men, not just skinny men, should be classified" as thin. Thus, raters would have been encouraged to rate programs and magazine genres with skinny, nonmuscular men the same way they rated programs and genres with lean, muscular men. If a fair proportion of programs and genres were rated "lean" because they featured skinny men instead of lean, muscular men, it would make sense to find little correlation (or even a negative correlation) between exposure to such programs and genres and disordered eating in males.

Finally, there was little variation in the eating disorder measures among males. Such floor effects would reduce the variance necessary to find the sought-after relationships. On the other hand, such floor effects may also demonstrate an overall lack of concern about weight reduction on the part of adolescent males. Such concerns may begin only when males reach adulthood, or not at all. In any case, it will be important to extend the findings presented here to additional samples of males to determine whether there are age differences in the relationship between male thin-ideal media exposure and disordered eating, or whether this relationship simply does not exist for males.

The finding that, for 12th-grade females, exposure to sports magazines was related to an increase in body dissatisfaction is intriguing. This finding seems to contradict that reported by Tiggemann and Pickering (1996). Their sample averaged 15.5 years old, whereas the portion of the sample here who exhibited the contrary relationship averaged 17.8 years old. It is possible that age will change a negative or nonexistent relationship between sports media exposure and body dissatisfaction into a positive one. Moreover, Tiggemann and Pickering studied exposure to televised sports, whereas this study involved sports magazines. Although there are no content analyses demonstrating this, it is possible that sports television depicts athletes engaging in their sport without the accompanying statistics like height, weight, diet, and regimen that sports magazines feature. This information may lead readers to compare their own "vital statistics" to those of the athletes and feel inadequate in comparison.

Because the analyses reported here were exploratory, it is difficult to say why the relationship between sports magazine exposure and body dissatisfaction for younger females was negative (though nonsignificant), yet positive for older females. A possible explanation derives from the fact that the examples of sports magazines listed in the exposure measure included Sports Illustrated and Sports Illustrated for Kids. Perhaps younger female adolescents who read sports magazines tend toward the child-appropriate versions, which may focus more on sport itself than on body shape. The adult versions, in contrast, may feature ideal-body images (e.g., the Sports Illustrated swimsuit issue) that influence the self-perceptions of those older female adolescents who read them. Moreover, recent media coverage of popular female athletes such as WNBA player Lisa Leslie has focused 
on the athletes' "sexy" characteristics, and female athletes are routinely asked to pose nude in advertisements with sexual double entendres like "just do it" printed below their sweat-slicked bodies. There is still obviously a need to empirically isolate the effects of exposure to sports media that emphasize what female athletes' body parts look like from those that emphasize what goals female athletes can achieve.

\section{Limitations and Future Directions}

One limitation of this study is that it did not include measures of participants' own sports activity. An adolescent's own involvement in sports should determine both her body-related attitudes and eating behaviors and her exposure to sports media. This study attempted to control for the influence of interest in sports as it might generate from one's own sports involvement, but the true relationship between sports media exposure and eating-disorder symptomatology would be best isolated with analyses controlling for participants' own athletic activity.

The study of media effects on eating disorders is difficult because it does not lend itself well to experimental investigation. Eating disorders are patterns of behavior that develop over time and cannot be induced or terminated by a single media-exposure session. The time-dependent nature of disordered eating is reflected in the relatively small effect sizes characteristic of this and other survey research employing cross-sectional techniques. Still, to this day, cross-sectional survey research has provided the richest pool of information available on the media exposure-eating disorder relationship, and especially valuable are studies that control for selective exposure to thin-ideal media based on interest in bodyimprovement media topics. However, causal arguments are and always will be difficult to substantiate in survey research. The bottom line is that this field of study desperately needs longitudinal research examining the impact of early media exposure on endorsement of the thin ideal and the development of eating disorders later in life. Continued investigation into the media exposure-eating disorder relationship in males is also needed. This would enable researchers to better understand how males respond to the masculine body ideal, but just as importantly, it would increase understanding of the processes underlying the corresponding relationship in females by providing a basis for comparison. Finally, because most young people are exposed daily to images of extreme thinness, but only a small subset develop full-blown eating disorders, it is imperative that researchers identify variables beyond sex and age that moderate or mediate the effects of exposure to thin-ideal media on eating disorders. Which young people are most likely to develop eating disorders as a result of exposure to "the body electric"? This important question awaits a more detailed answer.

\section{References}

American Psychiatric Association. (1994). Diagnostic and statistical manual of mental disorders (4th ed.). Washington, DC: Author.

Anderson, A. E. (1990). Males with eating disorders. New York: Brunner/Mazel. 
Anderson, A. E., \& DiDomenico, L. (1992). Diet vs. shape content in popular male and female magazines: A dose-response relationship to the incidence of eating disorders? International Journal of Eating Disorders, 11, 283-287.

Bandura, A. (1994). Social cognitive theory of mass communication. In J. Bryant \& D. Zillmann (Eds.), Media effects: Advances in theory and research (pp. 61-90). Hillsdale, NJ: Erlbaum.

Bearison, D. J., Bain, J. M., \& Daniele, R. (1982). Developmental changes in how children understand television. Social Behavior and Personality, 10, 133-144.

Biddle, S., Akande, A., Vlachopoulos, S., \& Fox, K. (1996). Towards an understanding of children's motivation for physical activity: Achievement goal orientations, beliefs about sport success, and sport emotion in Zimbabwean children. Psychology and Health, 12, 49-55.

Brand, P., Rothblum, E., \& Solomon, L. (1992). A comparison of lesbians, gay men, and heterosexuals on weight and restrained eating. International Journal of Eating Disorders, 11, 253-259.

Butcher, J. E. (1989). Adolescent girls' sex role development: Relationship with sports participation, self-esteem, and age at menarche. Sex Roles, 20, 575-593.

Dorr, A., Kovaric, P., \& Doubleday, C. (1990). Age and content influences on children's perceptions of the realism of television families. Journal of Broadcasting and Electronic Media, 34, 377-397.

Doubleday, C. N., \& Droege, K. L. (1993). Cognitive developmental influences in children's understanding of television. In G. L. Berry (Ed.), Children and television: Images in a changing sociocultural world (pp. 23-37). Newbury Park, CA: Sage.

Fouts, G., \& Burggraf, K. (1999). Television situation comedies: Female body images and verbal reinforcements. Sex Roles, 40, 473-481.

Freedman, R. (1984). Reflections on beauty as it related to health in adolescent females. In S. Golub (Ed.), Health care of the female adolescent (pp. 29-46). New York: Haworth Press.

Garner, D. M., \& Garfinkel, P. E. (1979). The Eating Attitudes Test: An index of the symptoms of anorexia nervosa. Psychological Medicine, 9, 273-279.

Garner, D. M., Garfinkel, P. E., Schwartz, D., \& Thompson, M. (1980). Cultural expectations of thinness in women. Psychological Reports, 47, 483-491.

Garner, D. M., Olmstead, M. P., \& Polivy, J. (1984). Development and validation of a multidimensional eating disorder inventory for anorexia nervosa and bulimia. International Journal of Eating Disorders, $2,15-34$

Harrison, K. (1997). Does interpersonal attraction to thin media personalities promote eating disorders? Journal of Broadcasting and Electronic Media, 41, 478-500.

Harrison, K., \& Cantor, J. (1997). The relationship between media exposure and eating disorders. Journal of Communication, 47, 40-67.

Hirt, E. R., Zillmann, D., Erickson, G. A., \& Kennedy, C. (1992). Costs and benefits of allegiance: Changes in fans' self-ascribed competencies after team victory versus defeat. Journal of Personality and Social Psychology, 63, 724-738.

Huesmann, L. R., Moise, J. F., \& Podolski, C. (1997). The effects of media violence on the development of antisocial behavior. In D. M. Stoff (Ed.), Handbook of antisocial behavior (pp. 181-193). New York: Wiley.

Irving, L. M. (1990). Mirror images: Effects of the standard of beauty on the self- and body-esteem of women exhibiting varying levels of bulimic symptoms. Journal of Social and Clinical Psychology, 9, 230-242. 
Levine, M. P., \& Smolak, L. (1996). Media as a context for the development of disordered eating. In L. Smolak (Ed.), The developmental psychopathology of eating disorders: Implications for research, prevention, and treatment (pp. 235-257). Mahwah, NJ: Erlbaum.

Maloney, M. J., McGuire, J. B., \& Daniels, S. R. (1988). Reliability testing of a children's version of the Eating Attitudes Test. Journal of the American Academy of Child and Adolescent Psychiatry, 27, 541543.

McNeal, R. B. (1995). Extracurricular activities and high school dropouts. Sociology of Education, 68, 62-80.

Meyers, P., \& Biocca, F. (1992). The elastic body image: An experiment on the effect of advertising and programming on body image distortions in young women. Journal of Communication, 42, 108-133.

Petersons, M., Phillips, E., \& Steinhaus, N. (1996). Prevalence of eating-disordered behaviors among fashion merchandising majors. Eating Disorders: The Journal of Treatment and Prevention, 4, 256263.

Pinhas, L., Toner, B. B., Ali, A., Garfinkel, P. E., \& Stuckless, N. (1999). The effects of the ideal of female beauty on mood and body satisfaction. International Journal of Eating Disorders, 25, 223-226.

Silverstein, B., Perdue, L., Peterson, B., \& Kelly, E. (1986). The role of the mass media in promoting a thin standard of attractiveness for women. Sex Roles, 14, 519-532.

Stice, E. (1998). Modeling of eating pathology and social reinforcement of the thin-ideal predict onset of bulimic symptoms. Behaviour Research and Therapy, 36, 931-944.

Stice, E., \& Shaw, H. E. (1994). Adverse effects of the media portrayed thin-ideal on women and linkages to bulimic symptomatology. Journal of Social and Clinical Psychology, 13, 288-308.

Stice, E., Schupak-Neuberg, E., Shaw, H. E., \& Stein, R. I. (1994). Relation of media exposure to eatingdisorder symptomatology: An examination of mediating mechanisms. Journal of Abnormal Psychology, 103, 836-840.

Tan, A. S. (1977). TV beauty ads and role expectations of adolescent female viewers. Journalism Quarterly, 56, 283-288.

Tan, A., Nelson, L., Dong, Q., \& Tan, G. (1997). Value acceptance in adolescent socialization: A test of a cognitive-functional theory of television effects. Communication Monographs, 64, 82-97.

Tiggemann, M., \& Pickering, A. S. (1996). Role of television in adolescent women's body dissatisfaction and drive for thinness. International Journal of Eating Disorders, 20, 199-203.

Virnig, A. G., \& McLeod, C. R. (1996). Attitudes toward eating and exercise: A comparison of runners and triathletes. Journal of Sport Behavior, 19, 82-90.

Whitman, W. (1855). Leaves of grass. Middlesex, UK: Penguin Books.

Wilson, B. J., \& Cantor, J. (1985). Developmental differences in empathy with a television protagonist's fear. Journal of Experimental Psychology, 39, 284-299.

Wilson, B. J., \& Smith, S. L. (1998). Children's responses to emotional portrayals on television. In P. A. Andersen (Ed.), Handbook of communication and emotion: Research, theory, applications, and contexts (pp. 533-569). San Diego, CA: Academic Press.

Wiseman, C. V., Gray, J. J., Mosimann, J. E., \& Ahrens, A. H. (1990). Cultural expectations of thinness in women: An update. International Journal of Eating Disorders, 11, 85-89. 